\title{
Formação do terapeuta ocupacional em gerontologia: contribuições de docentes de cursos de graduação em terapia ocupacional no Brasil
}

\author{
The education of occupational therapist in \\ gerontology: contributions of teachers from \\ undergraduate courses in occupational \\ therapy in Brazil
}

\author{
Maria Helena Morgani de Almeida ${ }^{1}$, Aline Buchalla Ferreira ${ }^{2}$, \\ Marina Picazzio Perez Batista ${ }^{3}$
}

\begin{abstract}
ALMEIDA, M. H. M.; FERREIRA, A. B.; BATISTA, M. P. P. Formação do terapeuta ocupacional em gerontologia: contribuições de docentes de cursos de graduação em terapia ocupacional no Brasil. Rev. Ter. Ocup. Univ. São Paulo, v. 22, n. 3, p. 289-297, set./dez. 2011.

RESUMO: INTRODUÇÃO: A capacitação de recursos humanos para a área gerontológica contribui para o enfrentamento dos desafios do envelhecimento. Com objetivo de aprimorar a formação na área de gerontologia do curso de Terapia Ocupacional da USP-SP desenvolveu-se pesquisa com docentes da área de gerontologia de diversos cursos de graduação em Terapia Ocupacional no Brasil. MÉTODO: O estudo qualitativo, exploratório e descritivo foi realizado em 2009 e 2010. Os dados foram obtidos por meio de questionário e analisados em seu conteúdo. Participaram do estudo 11 docentes, 8 lecionam em instituições de ensino superior públicas e $3 \mathrm{em}$ particulares. RESULTADOS: Os docentes consideram que as disciplinas proporcionam maior compreensão do processo de envelhecimento humano e, possibilidades de atuação junto à população idosa. Parte dos docentes refere a articulação teórico-prática como estratégia de ensino-aprendizagem. As mudanças na metodologia de ensino, com destaque para as metodologias ativas, foram citadas por 9 docentes. Alguns docentes identificam reduzida carga horária para a área. Todas as instituições adotam projetos de extensão para formação e 6 realizam atividades de pesquisa. CONCLUSÃO: As informações obtidas reafirmam parte das estratégias adotadas pelo curso de Terapia ocupacional da USP-SP na área de gerontologia: adequação de carga horária para formação, disciplinas específicas e articulação teórico-prática. Refletiu-se sobre a ampliação do uso de metodologias ativas como estratégia de ensino e aprendizagem no aprimoramento da formação em gerontologia oferecida pelo curso de Terapia Ocupacional da USP/SP.
\end{abstract}

DESCRITORES: Terapia Ocupacional; Gerontologia; Ensino superior; Docentes.

\footnotetext{
1. Profa. Dra. do Departamento de Fonoaudiologia, Fisioterapia e Terapia Ocupacional da Faculdade de Medicina da Universidade de São Paulo.Terapeuta Ocupacional. Doutorado pela Faculdade de Saúde Pública - Universidade de São Paulo, Faculdade de Medicina, Departamento de Fonoaudiologia, Fisioterapia e Terapia Ocupacional.

2. Aluna de graduação do curso de Terapia Ocupacional da Universidade de São Paulo, Faculdade de Medicina, Departamento de Fonoaudiologia, Fisioterapia e Terapia Ocupacional.

3. Terapeuta Ocupacional formada pela Universidade de São Paulo- Faculdade de Medicina. Departamento de Fonoaudiologia, Fisioterapia e Terapia Ocupacional. Mestranda em Ciências da Reabilitação pela Faculdade de Medicina da Universidade de São Paulo.

Endereço para correspondência: Rua Cipotânea, 51. Cidade Universitária 05360-000 - São Paulo, SP, Brasil. E-mail: hmorgani@usp. br
} 


\section{INTRODUÇÃO}

$\mathrm{O}$ envelhecimento populacional é um fenômeno mundial. Estima-se que em 2020 no Brasil, haverá um contingente superior a 30 milhões de pessoas idosas (RAMOS, 2005). Em decorrência de condições que freqüentemente incidem sobre aqueles que envelhecem, como doenças crônicas, incapacidades, perdas afetivas e de papéis sociais, as pessoas idosas desenvolvem múltiplas necessidades, que impõem desafios à sua atenção. Esses desafios devem ser enfrentados pela sociedade em geral, com destaque para gestores, administrações de serviços sociais e de saúde e profissionais inseridos nos diversos cenários de atenção a essa população.

Diante da complexidade que envolve a atenção às pessoas idosas e seu entorno, os profissionais, incluindo terapeutas ocupacionais, necessitam de uma formação que os instrumentalize na identificação das necessidades populacionais e na atuação em equipe interdisciplinar e multiprofissional.

A capacitação de recursos humanos especializados na área gerontológica constitui-se importante estratégia para o enfrentamento dos desafios atuais do envelhecimento, sendo prevista nas principais políticas para idosos, a estender-se da graduação ao aprimoramento e educação continuada (BRASIL, 1994, 1999, 2006).

Através da formação em gerontologia espera-se que o profissional aprenda a compreender as peculiaridades da população idosa e contribua para a promoção de seus direitos de cidadania, de sua independência e autonomia, de sua inclusão e participação social. Para tanto considerase necessário, organizar e aprofundar nos currículos de graduação, especialmente em saúde, conteúdos gerontológicos em disciplinas específicas, superando a habitual pulverização dos mesmos ao longo da formação, bem como criar e manter nos cursos, espaços de interlocução entre as distintas disciplinas.

Doll (2002) afirma que em cursos de especialização em gerontologia e geriatria devem ser introduzidos disciplinas, espaços e momentos que convoquem os alunos a pensar o envelhecimento como processo pessoal e não meramente como objeto de estudo distinto e distanciado do profissional. A reflexão aprofundada favorece a identificação e a prestação do cuidado humanizado: "a maneira como o profissional lida com sua própria velhice influencia a forma como lida com idosos" (Doll, 2002, p.1130). Acrescentase que reflexões acerca do próprio envelhecimento devem ser fomentadas desde a graduação o que contribuirá para combater estigmas, promover aproximação e preparar o futuro profissional para a atuação com a população idosa. Segundo Doll (2002) e Cabrera (2002) a estrita formação teórica pode incorrer no ensino de teorias como "verdades absolutas", sem que o aluno possa relativizá-las e compreender suas limitações que, segundo os autores, são confrontadas por meio de disciplinas práticas. Apesar das restrições, as disciplinas teóricas são imprescindíveis, pois além de fornecer o embasamento teórico, evitam a formação exclusivamente prática, restrita ao treinamento de funções específicas e a uma perspectiva isolada. Depreende-se que a integração entre atividades práticas e assistenciais - como estágios em instituições, visitas, entrevistas e aulas de laboratório - e disciplinas teóricas configura-se "estratégia cujo propósito é a formação de profissionais mais comprometidos e sensibilizados com a realidade social e com um melhor entendimento do indivíduo idoso" (CABRERA, 2002, p. 1135).

A formação do terapeuta ocupacional pela USP-SP para atuação em gerontologia foi incrementada a partir de 2004, basicamente por meio da reorganização e ampliação de atividades de ensino nesta área. Até o final do $1^{\circ}$ semestre de 2005 o curso oferecia exclusivamente uma disciplina teórica na área de gerontologia, denominada "Terapia Ocupacional em Geriatria e Gerontologia". Admitindose a importância desta área, introduziu-se no $2^{\circ}$ semestre de 2005 uma disciplina prática para alunos de $2^{\circ}$ e $3^{\circ}$ anos, denominada "Prática Supervisionada em Geriatria e Gerontologia" e, no $1^{\circ}$ semestre de 2007, a disciplina "Estágio Supervisionado em Geriatria e Gerontologia" para alunos do $4^{\circ}$ ano de graduação.

Por meio de um conjunto de disciplinas especificas com oferecimento regular - que articulam teoria e prática, além de orientações em pesquisa, o Curso de Terapia Ocupacional da USP-SP tem buscado contribuir para a formação profissional na área da gerontologia, ao possibilitar aos alunos: reflexão, (des)construção e compartilhamento de conceitos em relação ao envelhecimento e velhice, aprendizado de métodos e técnicas de avaliação e intervenção em Terapia Ocupacional e oportunidades de vivenciarem experiências em diversos contextos de atenção.

Neste estudo, objetivou-se identificar, junto a docentes de distintos cursos de Terapia Ocupacional no Brasil, contribuições de disciplinas sob sua responsabilidade e outras estratégias utilizadas para a formação na área gerontológica. Essas informações poderão constituir-se em valioso referencial para aprimoramento da formação em gerontologia pelo curso de Terapia Ocupacional pela USP-SP. 


\section{PROCEDIMENTOS METODOLÓGICOS}

O presente estudo teve apoio do Programa "Ensinar com pesquisa da Pró-reitoria de graduação da USP-SP" através da concessão de uma bolsa de graduação, foi aprovado pelo Comitê de Ética em Pesquisa da FMUSP, sob número 0810/09, e realizado nos anos de 2009 e 2010. O estudo caracterizou-se como exploratório e descritivo, foram obtidos dados de natureza qualitativa, por meio de aplicação de questionário não presencial. A população de estudo foi constituída por docentes responsáveis por disciplinas referentes à gerontologia em cursos de Graduação em Terapia Ocupacional no Brasil, com interesse expresso em termo de consentimento, em colaborar com o estudo.

Foram feitas solicitações às coordenações de cursos das diversas Instituições de Ensino Superior (IES) para fornecimento de formas de contato com os docentes que preenchessem os critérios para a participação no estudo. Os docentes com interesse expresso em participar e que forneceram endereço para correspondência, receberam material referente à pesquisa.

O questionário enviado versou sobre: disciplinas referentes à área de gerontologia sob responsabilidade do docente; tempo de oferecimento destas disciplinas; adequação considerada para a formação na área e previsão de mudanças em disciplinas quanto ao conteúdo e/ou metodologia de ensino. Os dados foram analisados em seu conteúdo, por meio da técnica de análise temática (MINAYO, 1993). Tomaram-se como referência para a análise de conteúdo, as variáveis previamente definidas, correspondentes às questões contidas no questionário, admitindo além destas, variáveis não previstas.

\section{RESULTADOS E DISCUSSÃO}

Participaram do estudo, 11 docentes das áreas de geriatria e gerontologia de diferentes cursos de Terapia Ocupacional do Brasil. Os contatos através das coordenações dos cursos foram poucos exitosos já que as informações relativas a essas coordenações, disponíveis nos sites das IES (Instituições de Ensino Superior) encontravam-se, em geral, desatualizadas. Como alternativa para estabelecimento de contatos com docentes, a presidência da Rede Nacional de Ensino em Terapia Ocupacional (RENETO) foi consultada e autorizou divulgação e convite para a pesquisa através dessa rede virtual.

Assim foram enviados convites a todos os docentes membros da RENETO solicitando que aqueles que desenvolvessem atividades de ensino nas áreas de geriatria e gerontologia se manifestassem quanto ao interesse em participarem do estudo e fornecessem endereço para envio de documentação referente à pesquisa. Dezenove docentes manifestaram interesse e receberam documentação e $11(61 \%)$ integraram de fato à pesquisa reenviando questionários preenchidos e termo de consentimento livre e esclarecido assinado.

Oito participantes (73\%) são da região Sudeste e 3 (27\%), do Sul do país; 8 (73\%) lecionam em IES públicas e $3(27 \%)$, em escolas particulares.

Os três docentes da região Sul trabalham em IES públicas. Em relação aos 8 docentes da região Sudeste, $3(37,5 \%)$ estão vinculados a instituições particulares e 5 $(62,5 \%)$, as públicas.

\section{Disciplinas oferecidas}

Oito docentes $(73 \%)$ oferecem mais de uma disciplina que de alguma forma aborda temas referentes à geriatria e gerontologia. Observam-se diferentes formas de oferecimento, 5 (45\%) oferecem disciplinas práticas específicas; 3 (27\%), práticas não-específicas; 4 (36\%), teóricas específicas; 4 (36\%), teóricas não-específicas e 6 $(55 \%)$ oferecem disciplinas específicas que denominam de "teórico-práticas". Foi citada por 1 (9\%) docente, a disciplina "Bioética" que apenas aborda algumas questões que são pertinentes às áreas de geriatria e gerontologia. Três $(27 \%)$ docentes oferecem disciplinas que distribuem sua carga horária com questões relativas à fase adulta e velhice.

No que refere ao oferecimento de disciplinas na graduação, Doll (2002) afirma que existem hoje no Brasil duas possibilidades: uma compreende a previsão do ensino de elementos da gerontologia em disciplinas já existentes; outra refere-se à oferta de disciplinas específicas.

Os docentes buscam abordar nas disciplinas, aspectos do processo de envelhecimento e assim sensibilizar e preparar os graduandos para que reconheçam o idoso como um indivíduo que apresenta necessidades diferentes dos demais adultos, estimulando-os a apreender e aplicar conceitos específicos na atenção a essa população (DIOGO; DUARTE apud MONTANHOLI, 2006).

Montanholi (2006) afirma que as atividades acadêmicas não devem se limitar a informar a respeito do envelhecimento, mas, formar profissionais que respeitem os limites e as peculiaridades decorrentes desse processo e reconheçam as modificações físicas, emocionais e sociais daquele que envelhece.

O valor de disciplinas relacionadas ao envelhecimento foi identificado em estudo conduzido junto a estudantes de enfermagem por Santos et al. (1990). Os autores observaram 
que os discentes que ainda não haviam tido, em seus currículos, disciplina relacionada ao envelhecimento, apresentaram atitudes desfavoráveis em relação ao idoso, modificando-as no decorrer do curso.

\section{Tempo de oferecimento das disciplinas}

O oferecimento de disciplinas é relativamente recente, já que $6(55 \%)$ docentes as oferecem a menos de 3 anos; 4 (36\%), entre 3 e 6 anos e apenas 1 docente (9\%) oferece a mais de 6 anos.

Os terapeutas ocupacionais, assim como outros profissionais da saúde têm sido chamados, atualmente, a atender ao crescente número de idosos, posicionando a graduação como estratégia fundamental para essa finalidade. Conforme Motta e Aguiar (2007) a transição epidemiológica e demográfica coloca a geriatria e gerontologia como uma especialidade com mercado em expansão, tanto no setor público como privado. A inclusão do processo de envelhecimento nos currículos de graduação é uma prioridade, sendo também necessário ampliar a discussão sobre o papel da pós-graduação, da educação permanente e da educação continuada a fim de fazer frente ao desafio de envelhecer com qualidade.

\section{Contribuições das disciplinas à formação profissional}

Os docentes consideram que as disciplinas, sejam elas práticas, teóricas ou "teórico-práticas", proporcionam maior compreensão do processo de envelhecimento humano em seus diferentes aspectos e particularidades. Sobre as disciplinas referem que:

"Contribuipara que o aluno compreenda o desenvolvimento do adulto ao idoso, o processo de envelhecimento e as alterações que podem ocorrer". (E3)

"Traz conhecimento do processo de envelhecimento humano, em seus múltiplos aspectos” (E11)

Os docentes estão promovendo em disciplinas de distintos formatos, a conscientização dos alunos em relação ao processo do envelhecimento e, desta forma, pode-se aumentar o interesse e qualificação do aluno pela e para a área (NOVAES, 2001).

Em pesquisa com egressos de enfermagem, Montanholi (2006) refere que os discentes valorizam o conhecimento científico e o consideram base para um bom planejamento da assistência. Além disso, os alunos relataram aumento do interesse pela área e visualizam a perspectiva profissional com idosos.

Os docentes participantes deste estudo sugerem que se deva compreender e ensinar gerontologia em sua complexidade. Conforme Metchnikoff apud Neri (2001) gerontologia refere-se ao

Campo multi e interdisciplinar que visa à descrição e à explicação das mudanças típicas do processo do envelhecimento e de seus determinantes genéticosbiológicos, psicológicos e socioculturais. Interessa-se também pelo estudo das características dos idosos, bem como das várias experiências de velhice e envelhecimento ocorrendo em diferentes contextos socioculturais e históricos (p. 54).

O conjunto dos participantes compartilha o ponto de vista semelhante ao formulado por Sá (2002, p. 1120):

Formar recursos humanos, na área da gerontologia, capazes de compreender o 'ser velho' e o processo do envelhecimento em suas dimensões conceituais, sociais, políticas, profissionais e éticas.

Outra contribuição das disciplinas, apontada pelos docentes, e comum aos três formatos, foi à promoção de maior entendimento, percepção e reflexão sobre as diferentes possibilidades de atuação do terapeuta ocupacional junto à população idosa. $\mathrm{O}$ contato promovido pelas disciplinas com as diversas possibilidades de atuação profissional nos distintos contextos de atenção se dá de forma teórica, prática e por meio da articulação entre a teoria estudada e as diferentes experiências práticas vivenciadas.

"Existe a possibilidade do aluno vivenciar junto à população idosa ações e estratégias conseguindo fazer correlações teórico-práticas. "(referindo-se a disciplina prática) (E9)

"Eles fazem atividades práticas em diversas instituições de atendimento aos idosos ao longo das duas disciplinas teóricas" (referindo-se a disciplinas teóricas) (E2) "Subsidio para que o aluno possa atuar diretamente junto a pessoas idosas nas mais diversas modalidades de atenção, na discussão e implementação de políticas e serviços para a população idosa e na pesquisa em gerontologia" (referindo-se a disciplinas "teóricoprática”) (E5)

Os participantes enfatizam que as disciplinas, sejam elas práticas ou teóricas, devam oferecer possibilidades de atuação, fundamentais à formação. De acordo com Cabrera (2002), a inserção de atividade assistencial no programa pedagógico justifica-se pela constante preocupação em formar profissionais que atendam a uma determinada realidade. 
Segundo Montanholi (2006), discentes relatam que, por meio do ensino da gerontologia envolvendo contato com o idoso, foi possível rever preconceitos.

Alguns conteúdos, referidos pelos docentes e presentes nas disciplinas, são também preconizados por Sá (2002) para a formação de recursos humanos em gerontologia. De acordo com o autor, para uma ação gerontológica de qualidade, o profissional deve, dentre outras ações, apreender e atuar sobre questões relativas ao envelhecimento e a velhice; compreender a natureza interdisciplinar da gerontologia, buscando ações compatíveis na área do ensino, da pesquisa e da prestação de serviços; ter competência teórico-crítica, técnico-operativa e ético-política.

\section{Estratégias para o bom aproveitamento de disciplinas}

Parte dos docentes refere que a articulação entre "teoria e prática" constitui-se como estratégia fundamental para que o aluno possa relacionar o conteúdo teórico à atuação prática do terapeuta ocupacional junto à população idosa.

"Considero que o conhecimento teórico, com atualização constante, e, a prática profissional em diversos contextos sociais e politicos e modalidades de atendimento me possibilitam efetivar o processo ensino-aprendizagem dos conteúdos programáticos da disciplina na formação do terapeuta ocupacional para atuar com o idoso" (E8)

Segundo Montanholi (2006), interações entre discentes e idosos, atrelado as discussões sobre temas relacionados ao envelhecimento modificam crenças, conceitos e valores, favorecendo a assistência à saúde desta população.

Pimenta (1995) comenta que o conceito de prática adotado por estágios curriculares vem se modificando na história da educação, superando a fase de observação e reprodução de modelos, em direção a uma prática mais teorizada.

Os docentes identificam ainda a importância dos estágios para a formação dos alunos.

"Existe a possibilidade do aluno vivenciar junto à população idosa ações e estratégias conseguindo fazer correlações teórico-práticas" (E11)

"Ajuda o aluno a ter maior compreensão da população alvo" (E7)

No espaço dos serviços, o mundo do trabalho materializa-se para o aluno. Esses se deparam com as demandas e na maioria das vezes, sem condições de responder a todas elas, o que os remete as questões dos direitos das pessoas, da cidadania e da ética que permeia o dia-a-dia dos serviços. A concretização do cenário da prática como espaço pedagógico só ocorre de fato quando nele se implicam os profissionais, os professores, os alunos e os usuários (WERNECK et al., 2010)

Os estágios parecem configurar-se, para os docentes, como espaços para que os alunos compreendam como a saúde é conduzida nos diferentes cenários. De acordo com Costa (1999), através dessa experiência os alunos são expostos aos distintos problemas dos serviços.

\section{Mudanças previstas nas disciplinas}

As mudanças relacionadas à metodologia de ensino foram citadas por nove docentes $(82 \%)$. Os docentes deram destaque à necessidade de sua constante modificação, a partir do reconhecimento da diversidade relacionada às turmas de discentes, e de outros fatores político-sociais que permeiam o conteúdo das disciplinas.

"Penso que a metodologia de ensino é algo dinâmico, que deve ser repensado a cada turma à qual a disciplina for oferecida" (E4)

"A cada oferta da disciplina as mudanças acontecem, o exercício da docência exige flexibilização de demanda do mercado, realidade social, politicas vigentes." (E6)

Alguns docentes avaliaram como positiva a adoção de metodologias ativas, e outros a identificaram como uma das modificações previstas na disciplina. Citaram que elas favorecem o aprendizado, participação dos discentes e articulação teórico-prática.

\footnotetext{
"No último semestre usei metodologias ativas e tive um resultado excelente. Os alunos se envolveram mais e relataram que se vêem atuando na área. Foi possivel observar que os alunos apreenderam melhor o conteúdo trabalhado" (E1)

"Nas aulas é importante trabalhar com metodologias ativas, considerando os contextos e as distintas modalidades de atenção, com o objetivo de favorecer a participação do estudante, apropriação do conteúdo proposto, a articulação teórico-prática, análise da realidade levando em consideração as especificidades da área, a demanda da população e o construto teórico que fundamenta a atuação do terapeuta ocupacional com idosos" (E9)
}

Os docentes apresentaram diversas estratégias de ensino utilizadas com o intuito de maior apreensão do conteúdo por parte dos alunos, dentre as estratégias citadas estão: estudo e discussão de casos clínicos, atividades 
práticas, elaboração de roteiros e realização de entrevistas com idosos e em serviços geriátricos, aproximação entre alunos que estão cursando a disciplina teórico-prática e aqueles que estão estagiando na área, apresentação de trabalhos em eventos da faculdade, observação direta, elaboração de portifólio, estudos dirigidos, projetos, ampliação de cenário de aprendizagem em disciplinas práticas.

Segundo Ramalhão (2006) quanto maiores os conhecimentos do docente sobre as diferentes estratégias pedagógicas, mais sucesso terá no alcance dos objetivos. Ao planejar uma aula, o professor deverá considerar o aluno/ grupo de alunos, o tipo de conteúdo, os objetivos e os meios de alcançar estes objetivos.

No que se refere aos cursos de Gerontologia e Geriatria, Doll (2002) alerta para o perigo de uma aprendizagem vazia e sem significado, propondo que essa deva abranger também elementos práticos e concretos. Depois da realização da atividade prática a que se conduzir reflexões e análises da prática observada ou realizada, possibilitando integração entre a aprendizagem teórica e prática.

Mitre (2010), trata das metodologias ativas de ensino-aprendizagem na formação em saúde referindo-se a elas como capazes de: desenvolver autonomia individual articulada intimamente ao coletivo, de desencadear uma visão de interdependência e de transdisciplinaridade, de ultrapassar os limites do treinamento puramente técnico, para efetivamente alcançar a formação do homem como um ser histórico, inscrito na dialética da ação-reflexão-ação.

As metodologias ativas caracterizam-se como abordagens pedagógicas progressivas de ensinoaprendizagem e implicam formar profissionais como sujeitos sociais com competências éticas, políticas e técnicas e dotados de conhecimento, raciocínio, crítica, responsabilidade e sensibilidade para as questões da vida e da sociedade.

As mudanças e atualizações de conteúdo também foram apontadas como necessárias para responder às distintas demandas da população em processo de envelhecimento e à crescente expansão deste campo em Terapia Ocupacional. Modificações de conteúdo e atualizações bibliográficas são requeridas para uma melhor formação dos futuros terapeutas ocupacionais, cabendo aos docentes estarem sempre atentos às necessidades de mudança e de flexibilização do conteúdo. Cinco docentes $(50 \%)$ prevêem mudanças de conteúdo e atualização bibliográfica.

"O conteúdo também pode sofrer alterações, pois o campo está em plena expansão". (E10)
Segundo Doll (2002) os cursos devem, por um lado, atualizar constantemente conhecimentos para acompanhar o desenvolvimento rápido das ciências e, por outro lado, devem ensinar aos alunos a se manterem atualizados. Esses devem conhecer os principais periódicos científicos e saber como ter acesso a eles. Isso significa também que as instituições que oferecem cursos nesta área devem dispor de biblioteca com acervo atualizado.

Alguns docentes, em especial os que ministram disciplinas não específicas em gerontologia, identificaram a reduzida carga horária destinada ao conteúdo específico de gerontologia como fator que dificulta um maior aprofundamento no tema, requerendo sua ampliação

“As disciplinas teóricas contêm uma carga horária muito
pequena (45 horas cada), seria necessário ampliação
para abordar conteúdos necessários para a formação do
aluno em gerontologia e T.O (...) as disciplinas teóricas
necessitam de uma carga horária maior, pois não temos
disciplinas voltadas somente para gerontologia, sendo
necessário condensar o conteúdo para abordar a fase
adulta e velhice." (E1)
"Acredito que o conteúdo desenvolvido oferece uma
formação superficial para o aluno atuar na área (...)
a organização dos módulos sempre esbarra na carga
horária prevista” (E4)
"Déficit na carga horária, bem como um número reduzido
de locais onde haja um T.O. para supervisionar a prátical
observação das discentes." (referindo-se a disciplinas
práticas) (E7)

O descontentamento dos docentes em relação à carga horária das disciplinas sintoniza-se com o preconizado pela literatura e em documentos oficiais. Conforme Diogo (2004) os currículos de cursos de graduação devem contemplar disciplinas especificas sobre gerontologia e geriatria, reconhecendo-se as múltiplas dimensões do processo de envelhecimento.

Especificamente para o curso de Enfermagem, segundo Diogo (2004), a Organização Panamericana da Saúde (OPAS) recomenda que não sejam oferecidos conteúdos geronto-geriátricos parciais integrados a outras disciplinas, para não se correr o risco de diluí-los ou reduzilos ao longo da grade curricular.

Conforme a Política Nacional de Saúde do Idoso (BRASIL, 1999),

A maioria das instituições de ensino superior brasileiras ainda não está sintonizada com o atual processo de transição demográfica e suas conseqüências médico-sociais. Há uma escassez de recursos técnicos e humanos para enfrentar a explosão desse grupo populacional no terceiro milênio. 
Diogo (2004) acrescenta que a falta de sintonia das Instituições de Ensino Superior brasileiras com as tendências do campo, se expressam ainda pela escassez de conteúdo nesta área nos currículos e falta de campos específicos para a prática, além da inexperiência do corpo docente.

$\mathrm{Na}$ Segunda Assembléia Mundial sobre o envelhecimento, ocorrida em Madrid, em 2002, foram discutidas prioridades entre as quais estava o treinamento de profissionais envolvidos no cuidado de saúde aos idosos, com expansão da instrução profissional nesta área tanto governamental como através das instituições de ensino. Nesta perspectiva se enquadra o incremento da gerontologia e geriatria nos currículos escolares (ONU, 2003).

\section{Outras estratégias adotadas pela IES para formação na área}

Todas as instituições adotam projetos de extensão como uma das estratégias para formação na área. Dentre os 11 docentes, 10 (91\%) citaram projetos de extensão, sendo alguns deles coordenados pelos próprios docentes participantes da pesquisa. Atividades ligadas a Universidade Aberta à Terceira Idade, Liga Acadêmica de Geriatria e Gerontologia, e Residência multiprofissional na área de saúde do idoso, foram algumas das estratégias de extensão citadas.

O papel de terapeuta ocupacional é muitas vezes desempenhado pelos próprios docentes em atividades de extensão, sendo esse um dos distintos papéis que desempenham. Rosa e Emmel (2001) discorrem sobre os diferentes papéis assumidos no exercício da docência: ensino, pesquisa, extensão e atividades administrativas. O exercício do duplo papel: de professor e de terapeuta, é uma particularidade do ensino na área da saúde, no qual o processo ensino-aprendizado vai sendo contextualizado pela relação professor-aluno-paciente.

As atividades de pesquisa também foram citadas por 6(55\%) participantes como estratégia para formação na área. A pesquisa constitui-se oportunidade para estruturar melhor o campo profissional já que através dela se desenvolvem capacidades para aproximar-se de novas tarefas e descobrir o necessário. A pesquisa é um instrumento não só de descobertas, mas um princípio formador (COSTA apud DOLL, 2002).

Segundo Motta e Aguiar (2007) a articulação "ensino-pesquisa-extensão" permite ao aluno exercício de seu papel social através de contribuições concretas a população e aos serviços
Dentre as estratégias relacionadas ao ensino foram citadas especializações na área e capacitação formal (mestrado e doutorado). A porcentagem de respostas que incluíram a formação complementar como estratégia foi de $36 \%$.

"Temos uma especialização com ênfase na área de Gerontologia e no, Programa de Ciências da Reabilitação (mestrado e doutorado) temos a sub-área saúde do idoso". (E3)

\section{Comentários finais dos docentes}

Em linhas gerais, os docentes versaram sobre a necessidade de uma ampliação das áreas de geriatria e gerontologia nos currículos dos cursos de Terapia Ocupacional e, da carga horária destinada as mesmas.

\footnotetext{
"Acredito que a área de geronto está crescendo e é um excelente campo de atuação para T.O., mas acredito que há a necessidade desta área ser reforçada nos cursos, com docentes em diferentes áreas de atuação, por exemplo, demência, reabilitação física, envelhecimento bem sucedido, programas de pré-aposentadoria, fortalecendo a atuação da T.O.” (E5)
}

Conforme Freitas et. al. (2002) as áreas de geriatria e a gerontologia abrigam profissionais que precisam ser preparados para melhor assistir a população idosa. Logo, a formação de recursos humanos se coloca como fundamental para despertar o compromisso profissional ativo, considerando a diversidade e o conhecimento da realidade. Assim, "os conhecimentos em torno do homem tomam corpo e se tornam críticos e reflexivos, a partir de um novo olhar sobre a realidade vivenciada" (CAMACHO, 2002, p.231).

\section{CONCLUSÃO}

A maioria dos docentes é responsável por disciplinas em instituições públicas e evidencia-se equilíbrio quanto ao tempo de oferecimento das disciplinas, entre os que têm até 3 anos e os que têm mais de 3 anos de oferecimento.

Embora os docentes relatem experiência semelhante a USP - SP, quanto ao número de disciplinas oferecidas que tratam de temas das áreas de geriatria e gerontologia (em média duas por docente), o fazem, de forma distinta da USP-SP. Os docentes adotam disciplinas específicas e não específicas e, ainda que grande parte considere insuficiente a carga horária destinada à área, identifica importantes contribuições das disciplinas para a formação profissional 
como: compreensão sobre o processo de envelhecimento humano em sua complexidade e possibilidades de atuação em distintas modalidades.

Os docentes nas demais IES, assim como na USP-SP, reconhecem e adotam a articulação teórico-prática como estratégia fundamental para o bom aproveitamento dos alunos nas disciplinas. Alguns prevêem manter o uso de metodologias ativas e outros prevêem adotá-las.

A revisão constante do conteúdo e da bibliografia utilizada é reconhecida como importante, tanto nas demais IES como na USP-SP.

Esses profissionais têm integrado estratégias para a formação qualificada na área atrelando ao ensino, atividades nos âmbitos da extensão de serviços à comunidade, formação complementar e pesquisa. As informações fornecidas pelos docentes estão estreitamente relacionadas à literatura atual sobre o ensino de geriatria e gerontologia e em consonância com as estratégias adotadas pela USP-SP.
Nesse sentido destacam-se na USP-SP, programas de concessão de bolsas de graduação. Esses programas têm contribuído para a permanência estudantil, para participação de alunos em projetos de pesquisa e extensão e possibilitado ampliar e qualificar o ensino, a extensão e a pesquisa nas diversas áreas profissionais, incluindo a Terapia Ocupacional.

As informações obtidas junto aos docentes reafirmam parte das estratégias adotadas pelo curso de Terapia Ocupacional da USP-SP na área de gerontologia, tais como: atenção e busca de adequação à carga horária destinada para formação, oferecimento preferencial de disciplinas específicas e articulação teórico-prática. Ainda, permitiram refletir sobre os benefícios da ampliação do uso de metodologias ativas como estratégia de ensino e aprendizagem, contribuindo para o aprimoramento da formação em gerontologia oferecida pelo curso de Terapia Ocupacional da USP-SP.

\begin{abstract}
ALMEIDA, M. H. M.; FERREIRA, A. B.; BATISTA, M. P. P. The education of occupational therapist in gerontology: contributions of teachers from undergraduate courses in occupational therapy in Brazil. Rev. Ter. Ocup. Univ. São Paulo, v. 22, n. 3, p. 289-297, set./dez. 2011.

ABSTRACT: INTRODUCTION: The human resource training in gerontology contributes to face the challenges of aging. In order to improve the education process of Occupational Therapy USP-SP undergraduate course in the Gerontology area, a research was developed with teachers from several Occupational Therapy undergraduate courses in Brazil. METHOD: The qualitative, exploratory and descriptive study was conducted in 2009 and 2010. Data were collected through a questionnaire and analyzed in their content. Eleven teachers, which eight of them teaches in public universities and three in private ones, participated in the study. RESULTS: Teachers believe that the disciplines provide greater understanding of the human aging process and increase the possibilities of working with elderly. Some of the teachers concerned articulation of theory and practice as a teaching learning strategy. Changes in teaching methodology, with emphasis on active methodologies, were cited by nine teachers. Some teachers identify a reduced hour load for the area in their courses. All faculties carry out extension project and 6 of them research activities in their courses. CONCLUSION: Data reaffirmed some of the strategies adopted by the gerontology area in Occupational Therapy undergraduate course at USP-SP: hour load devoted for training, specific disciplines and theory and practice articulation. It was possible to reflect on increasing the use of active methodologies as a teaching learning strategy to improve the gerontology training in Occupational Therapy USP- SP undergraduate course.
\end{abstract}

KEY WORDS: Occupational therapy; Geriatrics; Education, higher; Faculty.

\title{
REFERÊNCIAS
}

BATISTA, R. S.; MENDONÇA, J. M. G.; PINTO, N. M. M.; MEIRELlES, C. A. B.; PORTO, C. P.; MOREIRA, T.; HOFFMANN, L. M. A. Metodologias ativas de ensinoaprendizagem na formação profissional em saúde: debates atuais. Ciênc. saúde coletiva, v.13, n. 2, p. 2133-44, 2008.
BRASIL. Lei ${ }^{\circ}$ 8.842. Dispõe sobre a Política nacional do idoso cria o Conselho Nacional do Idoso e dá outras providências. Brasília, 1994.

BRASIL. Ministério da Saúde. Portaria 1395/GM. Política de 
Saúde do Idoso. Brasília, 1999.

BRASIL. Ministério da Saúde. Portaria ${ }^{\circ}{ }^{2} .528$. Aprova a Política Nacional de Saúde da Pessoa Idosa. Brasília, 2006

CABRERA, M. Integração educação-assistência. In: FREITAS, E. V.; PY, L.; NERI, A. L.; CANÇADO, F. A. X.; GORZONI, M. L.; ROCHA, S. M. Tratado de geriatria e gerontologia. Rio de Janeiro: Guanabara Koogan, 2002. p.1135-8.

CAMACHO, A. C. L. F. A gerontologia e a interdisciplinaridade: aspectos relevantes para a enfermagem. Rev. Latino-Amer. Enferm., v. 10, n. 2, p. 229-33, 2002

COSTA, W. C. Morte e desenvolvimento humano. In: PY, L. Finitude: uma proposta para reflexão e prática em gerontologia. Rio de Janeiro: NAU, 1999. p. 55-63.

DIOGO, M. J. D. E. Formação de recursos humanos na área da saúde do idoso. Rev. Latino-Amer. Enferm., v. 12, n. 2, p. 280-2, 2004 .

DOLL, J. Planejamento e avaliação de programas educacionais, visando à formação de recursos humanos em geriatria e em gerontologia. In: FREITAS, E. V.; PY, L.; NERI, A. L.; CANÇADO, F. A. X.; GORZONI, M. L.; ROCHA, S. M. Tratado de geriatria e gerontologia. Rio de Janeiro: Guanabara Koogan, 2002. p.1125-34.

FREITAS, M. C.; MARUYAMA, S. A. T.; FERREIRA, T. F.; MOTTA, A. M. A. Perspectivas das pesquisas em gerontologia e geriatria: revisão da literatura. Rev. Latino-Amer. Enferm., v. 10, n. 2, p. 221-228, 2002.

MINAYO, M. C. S. O desafio do conhecimento: pesquisa qualitativa em saúde. 2a. ed. São Paulo: Hucitec Abrasco, 1993.

MONTANHOLI, L. L.; TAVARES, D. M. S.; OLIVEIRA, G. R.; SIMOES, A. L. A. Ensino sobre idoso e gerontologia: visão do discente de enfermagem no Estado de Minas Gerais. Texto Contexto - Enferm., v. 15, n. 4, p. 663-71, 2006.

MOTTA, L. B.; AGUIAR, A. C. Novas competências profissionais em saúde e o envelhecimento populacional brasileiro: integralidade, interdisciplinaridade e intersetorialidade. Ciênc. Saúde Coletiva, v. 12, n. 2, p. 363-72, 2007.

Aceito para publicação: 22/11/11

Recebido para publicação: 02/12/11
NERI, A. L. Palavras chaves em gerontologia. Campinas: Alínea, 2001.

NOVAES, M. R. V. As representações sociais dos alunos de graduação em enfermagem sobre "Ser Velho" $e$ "Cuidar de Velhos". 2001. 118f. Dissertação (Mestrado Prática de Saúde Pública). - Faculdade de Saúde Pública, Universidade de São Paulo, São Paulo, 2001.

ONU. Organização das Nações Unidas. Plano de ação internacional para o envelhecimento; 2002. Trad. Arlene Santos. Brasília (DF): Secretaria Especial dos Direitos Humanos, 2003.

PIMENTA, S. O estágio na formação de professores: unidade teoria e prática? 2a. ed. São Paulo: Cortez, 1995.

RAMALHÃO, A. B. Ensino na área da saúde: aproximações às estratégias de ensino-aprendizagem dos professores de Terapia Ocupacional. 2006. 229f. Dissertação (Mestrado Ensino em Ciências da Saúde) - Escola Paulista de Medicina, Universidade Federal de São Paulo, São Paulo, 2006.

RAMOS, L. R. A mudança de paradigma na saúde e o conceito de capacidade funcional. In: SUMSION, T. Guia de medicina ambulatorial e hospitalar. São Paulo: Manole, 2005. p.1-7.

ROSA, S. D.; EMMEL, M. L. G. Reflexões sobre os diferentes papéis assumidos pelo terapeuta ocupacional enquanto professor universitário. Cad. Ter. Ocup. UFSCar, v. 9, n. 1, p. 1-15, 2001.

SA, J. L. M. A formação de recursos humanos em gerontologia: fundamentos epistemológicos e conceituais. In: FREITAS, E. V.; PY, L.; NERI, A. L.; CANÇADO, F. A. X.; GORZONI, M. L.; ROCHA, S. M. Tratado de geriatria e gerontologia. Rio de Janeiro: Guanabara Koogan, 2002. p. 1119-24.

SANTOS, L. L. C.; BUB, L. I. R.; MENDES, N. T. C. Levantamento dos conteúdos de Geriatria e Gerontologia dos currículos dos cursos de graduação em enfermagem em relação ao idoso apresentada por seus professores e estudantes. Rev. Ciên. Saúde, v. 9, n. 2, p. 75-108, 1990.

WERNECK, M. A. F.; SENNA, M. I. B.; DRUMOND, M. M.; LUCAS, S. D. Nem tudo é estágio: contribuições para o debate. Ciênc. Saúde Coletiva, v.15, n. 1, p. 221-31, 2010. 